\title{
Arazi kullanım türü değişikliklerinin toprakların bazı fiziksel ve kimyasal özelliklerine etkisinin araştırılması
}

\section{Investigation of the effects of land use type changes on some soil physical and chemical properties}

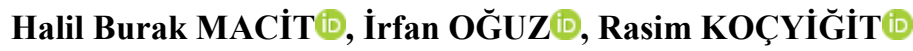 \\ Tokat Gaziosmanpaşa Üniversitesi Ziraat Fakültesi Toprak Bilimi ve Bitki Besleme Bölümü-Tokat \\ Sorumlu yazar (Corresponding author): İ. Oğuz, e-posta (e-mail): irfan.oguz@gop.edu.tr \\ Yazar(lar) e-posta (Author e-mail): halilburakmacit@gmail.com, rasim.kocyigit@gop.edu.tr
}

\section{MAKALE BİLGİSİ}

Alınış tarihi 29 Eylül 2020

Düzeltilme tarihi 15 Ocak 2021

Kabul tarihi 15 Ocak 2021

\section{Anahtar Kelimeler:}

Arazi kullanımı

Toprak özellikleri

Erozyon

Zile

\begin{abstract}
ÖZ
Tokat-Zile ilçesine bağlı Binbaşığlu ve Belpınar Köylerinde yürütülen bu çalışmada, arazi kullanım türü değişiklilerinin toprakların bazı fiziksel ve kimyasal özelliklerine etkisi araştırılmıştır. Araştırma konuları Belpınar Köyü sürekli tarım arazisi (A), Belpınar Köyü tarım arazi kullanım türünden orman arazi kullanım türüne çevrilmiş arazi (B), Binbaşığlu Köyü sürekli tarım arazisi (C), Binbaşığlu Köyü sürekli mera arazisi (D), Binbaşıŏlu Köyü sürekli orman arazisi (E) ve Binbaşıŏglu Köyü ormandan tarıma çevrilmiş arazi (F). Çalışma kapsamında farklı arazi kullanımına sahip toprakların aşınıma duyarlılık, tekstür, çok ince kum, iskelet yüzdesi, agregat stabilitesi, hacim ağırlı̆̆ı, dispersiyon oranı, hidrolik kondaktivite, kireç, $\mathrm{pH}, \mathrm{EC}$ ve organik madde gibi özellikleri değerlendirilmiştir. Araştırma konuları dispersiyon oranları \%15'in altında olmus ve erozyona dayanıklı topraklar olarak değerlendirilmiştir. Benzer şekilde, araştırma konuları aşınıma duyarlılık değerleri az ve orta derecede aşınabilir topraklar olarak belirlenmiştir. Sürekli mera ve orman arazilerinde yeterli vejetasyonunun olmaması toprakların organik madde içeriğinin ve agregat stabilitesinin yetersiz olmasında etkili olmuştur. Sürekli tarım, ormandan tarıma dönüştürülen arazi ve tarımdan ormana dönüştürülen arazilerde aradan geçen sürenin 10 yıldan az olması nedeniyle, beklenen olumlu ve olumsuz bariz değişimler gözlenememiştir.
\end{abstract}

\section{ARTICLE INFO}

Received 29 September 2020

Received in revised form 15 January 2021

Accepted 15 January 2021

\section{Keywords:}

Land use

Soil properties

Erosion

Zile

\begin{abstract}
This study was carried out to investigate the effects of land use changes on some soil physical and chemical properties in Binbaşığlu and Belpınar Villages of Tokat-Zile district. Research topics are as; Belpınar Village continuous farmland (A), Belpınar Village from farmland converted to forestland (B), Binbaşıoğlu Village continuous farmland (C), Binbaşıoğlu Village continuous grassland (D), Binbaşığlu Village continuous forestland (E) and Binbasioglu Village from forestland convert to farmland (F). Soil erodibility, texture, very fine sand, coarse material, aggregate stability, bulk density, dispersion ratio, hydraulic conductivity, lime content, $\mathrm{pH}, \mathrm{EC}$ and organic matter of soils were evaluated. Dispersion ratios were below $15 \%$ and were evaluated as resist to erosion. Similarly, the soil erodibility values of research subjects have been identified low-medium erodible soils. Lack of sufficient vegetation in continuous pasture and forestlands has been effective in insufficient organic matter content and aggregate stability of soils. The expected positive and negative changes could not be observed due to less than 10 years of continuous agriculture, forest-to-agricultural and agricultural-toforestland.
\end{abstract}

\section{Giriş}

Arazi kullanım planlamasında en uygun arazi kullanım seçeneklerinin belirlenmesi ve uygulanması amacıyla arazi ve toprak potansiyeli, mevcut arazi kullanımı, çeşitli alternatiflerin ekonomik ve sosyal koşullarının sistematik olarak değerlendirilmesidir (Ufot ve ark. 2016). Sürdürülebilir tarım için, tarımsal faaliyetlerin toprak yapısına uygun olması gerekmektedir. Çünkü aşırı toprak işleme, yıkanma ve toprak erozyonu gibi farklı nedenlerden dolayı kısa zaman içerisinde toprak kalitesi bozulabilmektedir (Kiflu ve Beyene 2013).

Günümüzde orman arazileri hızlı bir şekilde tarım ya da mera arazilerine dönüştürülmektedir (Duguma ve ark. 2010). 
Arazi kullanımındaki değişimler özellikle orman arazilerinin bozulması ve tarım arazileri lehine alan azalması, kuru tarım alanlarının bozulması, şehirleşme ile verimli tarım alanlarının azalması, arazi terki gibi nedenlerle meraya dönüşüm gibi faktörlere bağlı olarak meydana gelmektedir (Scheffler ve ark. 2011). Bu tür değişiklikler alansal ve zamansal olarak toprak özelliklerini de etkilemektedir. Arazi kullanımındaki değişikliklerin toprak özellikleri üzerinde etkisinin araştırıldığı bir çalışmada, ormandan tarımsal kullanıma dönüşümün toprağın agregat stabilitesi, organik karbon ve organik madde içeriğini azalttığı, verimliliğini düşürdüğü ifade edilmiştir (Hartemink ve ark. 2008).

Mera arazilerine dönüştürülen orman arazilerinin bir kısmında organik madde içeriği artarken (Lemenih ve ark. 2005), bazı yerlerde ise azaldı $\breve{g} 1$ yapılan çalışmalarda ifade edilmiştir (Powers 2004). Uygun olmayan arazi kullanımından dolayı organik madde içeriği azalmakta ve toprak kalitesi bozulmaktadır (Lal 2002). Uygun amenajman ve arazi kullanımı toprağın organik madde içeriğinin artmasına neden olmaktadır (Baker ve ark. 2007). Organik madde içeriği ile agregatlaşma arasında çok yakın bir ilişki söz konusudur (Shepherd ve ark. 2001). Ancak bazı durumlarda aralarındaki ilişki orta ya da çok zayıf olabilmektedir (Holeplass ve ark. 2004). Tarım arazilerinde ise, toprak işlemeye bağlı olarak toprak strüktürü ve organik karbon içeriği azalmaktadır (Eynard ve ark. 2004).

Banger ve ark. (2009), Endonezya'nın Bali adasında yamaç arazi üzerinde yer alan dört farklı arazi kullanımı altındaki toprakların, $0-5 \mathrm{~cm}, 5-15 \mathrm{~cm}, 15-30 \mathrm{~cm}$ ve $30-60 \mathrm{~cm}$ toprak derinliğine göre organik madde içeriğini araştırdıkları çalışmada tüm derinliklerde toprağın organik madde içeriğinin arazi kullanım türüne göre değiştiğini belirlemişlerdir.

Oral (2010) Karasu Bölgesi'ndeki arazi kullanım değişiminin toprak solunumu ve elementel karbon üzerine olan etkisini araştırmıştır. Orman ve ormansızlaştırılmış yerlerden almış olduğu 900 adet toprak örnekleri analiz sonuçlarına göre, arazi kullanımı değişimi nedeniyle, ormansızlaştırılmış alanlara göre, ormanlık alanlardaki elementel karbonun \%27 ve toprak solunumunun \%34 oranlarında daha yüksek olduğunu bildirmiştir.

Maral (2016) tarafindan Kastamonu civarındaki farklı arazi kullanımlarının (orman, tarım ve mera) bazı toprak özellikleri, karbon ve azot depolama oranları üzerine olan etkilerini araştırmıştır. Sonuç olarak, tarım alanının en düşük karbon (C) ve azot (N) miktarına, en az karbon ve azot depolama kapasitesine ve en düşük $\mathrm{C} / \mathrm{N}$ oranına sahip olduğunu tespit etmiştir. Orman ve mera alanlarında ise bu oran birbirine yakın sonuçlar göstermiştir.

Dias ve ark. (2019), Brezilya'da bulunan bir Ferralsol' ün kimyasal özellikleri ve topraktaki organik madde fraksiyonları üzerine arazi kullanım türlerinin etkisini araştırmışlardır. Organik tarım alanlarında, yüksek $\mathrm{pH}, \quad \mathrm{P}$ içeriği ve baz doygunluğu nedeniyle diğer tarımsal yönetim sistemlerinden farklı olmuştur. Orman alanının tarım alanlarına dönüştürülmesi toprakta kimyasal verimliliğin azalmasına yol açmıştır. Çalışma sonunda söz konusu arazilerde toprak işlemeli organik tarım ile organik maddeyi artırıcı toprak işlemesiz tarım uygun seçenekler olarak önerilmiştir.

Özdemir (2019) tarafından Manisa ili Kargınışıklar ve Hoşçalar Köylerinde farklı arazi kullanım türleri (orman, mera ve tarım) altında yer alan arazilerde yürütülen çalışmada toprakların fiziksel ve kimyasal özelliklerinin arazi kullanım şekillerine göre belirgin değişiklik göstermediği tespit edilmiş; değişikliğin toprak derinliğine bağlı olarak olduğu belirlenmiştir.

Arazi kullanım türlerinde meydana gelen değişikliklerin toprak özelliklerine olası etkilerinin araştırıldığ 1 çok sayıda çalışmalar olmakla birlikte, yarı kurak iklim koşullarına sahip çalışma yerinde daha önce yürütülmüş temel arazi kullanımlarındaki dönüşümlerin bir arada değerlendirildiği literatür bilgisine rastlanılmamıştır.

Tokat-Zile ilçesinde yürütülen bu çalışmada, tarım arazilerinin ormana dönüşümü veya tersi uygulamaların toprak özelliklerine olası etkilerini belirlemek amaçlanmıştır. Çalışmada, sürekli orman, sürekli tarım ve sürekli mera arazi kullanım türleri altındaki topraklara ait bazı fiziksel ve kimyasal özellikler, kullanım değişikliklerine maruz kalmış alanlarla karşılaştırılmıştır. Elde edilen bulguların yöre topraklarının sürdürülebilir yönetimine katkı sağlayacağı düşünülmektedir.

\section{Materyal ve Yöntem}

Çalışma, Tokat-Zile ilçesine bağlı Binbaşığlu ve Belpınarı köyleri arazilerinde yürütülmüştür (Şekil 1). Zile ilçesinin doğusunda Turhal, güneyinde Artova ve Yozgat iline bağlı Kadışehri, batısında Çekerek ile Amasya'nın Göynücek ilçesi, kuzeyinde ise Amasya ili bulunmaktadır. Zile ilçesi genel yüzölçümü 1512 km² dir. Zile ilçesi, İç Anadolu ile Karadeniz arasında geçit iklimine sahip olup, yazları sıcak ve kurak, kışları yağışlı ve soğuktur. Uzun yıllar ortalama yağışı $455 \mathrm{~mm}$, ortalama sicaklığ $11.6^{\circ} \mathrm{C}$ ve ortalama bağıl nemi \%69'dur (MGM 2019).

Çalışma, yöreyi temsil etmesi, birbirine yakın konumda olması ve farklı eğimlere sahip orman, mera ve tarım arazi kullanım türlerini içermesi koşulları dikkate alınarak Zile ilçesine bağlı Binbaşığlu ve Belpınarı Köylerinde yürütülmüştür. Çalışma, buğday-nadas ekim nöbeti yapılan tarlalar, doğal mera ve doğal orman arazilerinde yürütülmüştür. Yörede yaygın arazi kullanım türleri dikkate alınarak altı farklı arazi kullanım türü araştırma konuları olarak belirlenmiştir. $\mathrm{Bu}$ arazi kullanım türleri Belpınar Köyü sürekli tarım arazisi (A), Belpınar Köyü tarım arazi kullanım türünden orman arazi kullanım türüne çevrilmiş arazi (B), Binbaşığlu Köyü sürekli tarım arazisi (C), Binbaşığlu Köyü sürekli mera arazisi (D), Binbaşıŏlu Köyü sürekli orman arazisi (E) ve Binbaşığlu Köyü ormandan tarıma çevrilmiş arazisi (F) olarak ele alınmıştır. B ve F konularında meydana gelen arazi kullanım türü değişiklikleri 10 yıldan daha az sürede gerçekleştirilmiştir.

Çalışma yerlerinde her araştırma konusundan beşer tekerrürlü olacak şekilde yüzey toprak örnekleri $(0-20 \mathrm{~cm}$ derinlik) alınmış, toplam olarak 30 adet noktada arazi çalışması yapılmıştır. Analize hazır hale getirilen toprak örneklerinde toprak reaksiyonu $(\mathrm{pH})$ : saf su ile 1:2 oranında sulandırılmış toprak:su süspansiyonunda (Tüzüner 1990), elektriki iletkenlik (EC): satürasyon ekstraktında iletkenlik aleti ile (Tüzüner 1990), kireç (\%): Scheibler kalsimetresinde (Tüzüner 1990), organik madde $(\%)$ : modifiye Walkley-Black metoduna göre (Tüzüner 1990), tekstür (\%): Bouyoucous Hidrometre yöntemine göre (Tüzüner 1990), çok ince kum(\%): aşınıma duyarlılığı belirlemek amacıyla, eleme ile (Tüzüner 1990), hacim ağırlığı $\left(\mathrm{g} \mathrm{cm}^{-3}\right)$ : silindir yöntemi ile (Tüzüner 1990), hidrolik geçirgenlik $\left(\mathrm{mm} \mathrm{h}^{-1}\right)$ : toprakların bünye bilgilerinden yararlanarak SPAW adlı yazilımla (Saxton ve Rawls 2006), dispersiyon oranı (\%): toprağın su ile dispers edilmesiyle belirlenen silt ve kil fraksiyonlarının, mekanik analizle 


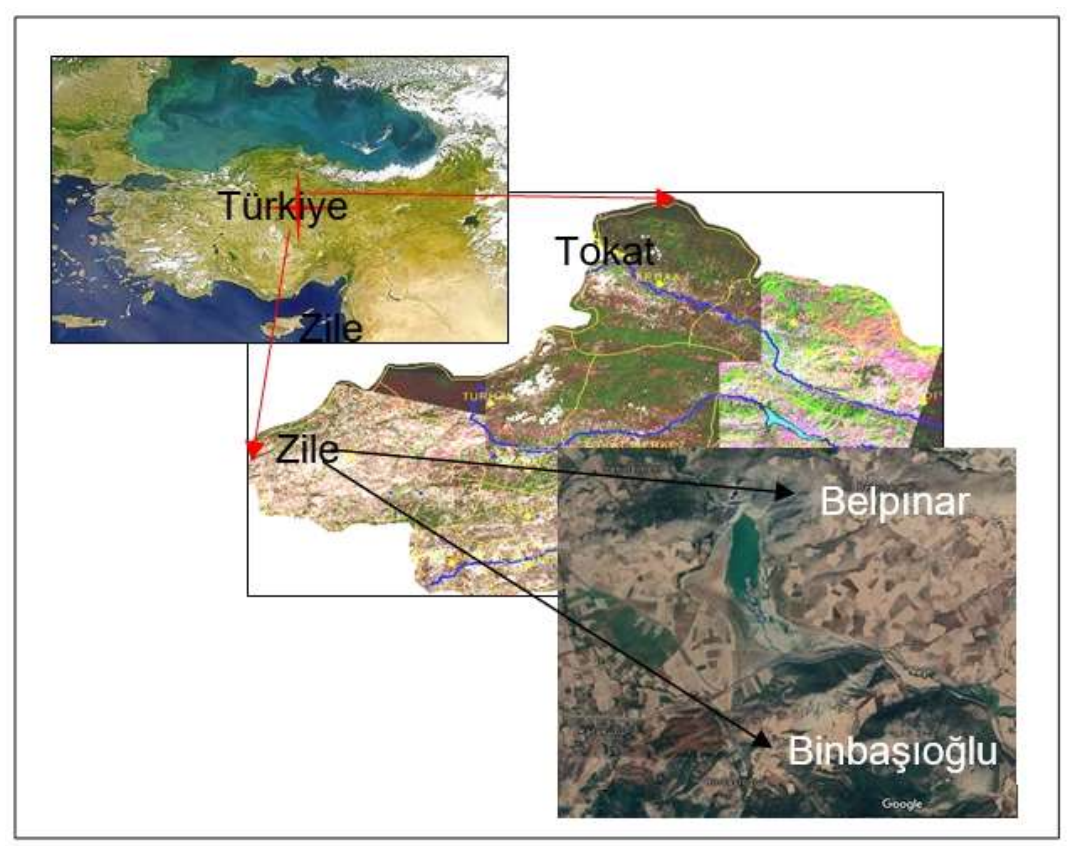

Şekil 1. Çalıșma yeri haritası.

Figure 1. Map of the study area.

belirlenen silt ve kil fraksiyonlarına oranlanmasıyla (Bryan 1968), agregat stabilitesi (\%): sslak eleme aleti ile (Tüzüner 1990), toprakların aşınıma duyarlılığı (K faktörü) laboratuvar analizine dayalı olarak ampirik eşitlikten yararlanılarak (Wischmeier ve Smith 1978) belirlenmiştir.

Her araștırma konusu için olmak üzere $0-20 \mathrm{~cm}$ derinlikten, 5 tekerrürlü olarak alınan toprak örneklerine ait toprak özellik değerleri normal dağılım gösterip göstermemesi kontrol edilmiştir. Normal dağılım göstermesi durumunda parametrik $t$ testi, aksi durumda ise nonparametrik Mann-Whitney $U$ testi ile aralarındaki farklılığın önemli olup olmadığı karşılaştırılmıştır. Her araştırma konusu için ele alınacak toprak özelliklerinin tanımlayıcı istatistiksel analizleri yapılmıştır (SPSS 2011).

\section{Bulgular ve Tartışma}

Çalışmada, sürekli tarım, mera ve orman arazisi olarak yönetilen toprakların bazı özellikleri ile kısa zamanda ormandan tarım arazisine dönüştürülmüş veya tarım arazisi iken orman arazisine dönüştürülmüş arazilerin özellikleri karşılaştırılmıştır.

Araştırma konularını kapsayan 5 bölgeden, beşer tekerrürlü olarak alınmış toprak örneklerinin belirlenen toprak özelliklerine ait tanımlayıcı istatistik verileri Çizelge 1'de verilmiştir. Toprak örneklerinin bazı fiziksel ve kimyasal analiz sonuçları ise Çizelge 2'de verilmiştir. Toprak özelliklerindeki değişkenlik \% varyasyon katsayısına göre üç gruba ayrılmıştır. Yüzde varyasyon katsayısı 15 'ten küçük olanlar düşük derecede değişken, 16 ile 35 arası olanlar orta derecede değişken ve 36'dan büyük olanlar yüksek derecede değişken olarak sınıflandırılmıştır (Upchurch ve ark. 1988).

A konusunda aşınıma duyarlılık, kum, kil, hacim ağırlığı, dispersiyon oranı, hidrolik geçirgenlik ve $\mathrm{pH}$ değerleri düşük değişkenlik, silt, çok ince kum, agregat stabilitesi, kireç ve EC orta değişkenlik ve iskelet yüzdesi ve organik madde değerleri yüksek değişkenlik göstermiştir. B konusunda kum, kireç, $\mathrm{pH}$ düşük değişkenlik, aşınıma duyarlılık, silt, kil, iskelet yüzdesi, hacim ağırlığı, dispersiyon oranı ve EC orta değişkenlik ve çok ince kum, agregat stabilitesi, hidrolik geçirgenlik ve organik madde yüksek değişkenlik göstermiştir. C konusunda kum, kil, hacim ağırlığı, dispersiyon oranı, kireç ve $\mathrm{pH}$ düşük değişkenlik, aşınıma duyarlılık, silt, çok ince kum, EC ve organik madde orta değişkenlik ve iskelet yüzdesi, agregat stabilitesi ve hidrolik geçirgenlik yüksek değişkenlik göstermiştir. D konusunda hacim ağırlığı, kireç ve $\mathrm{pH}$ düşük değişkenlik, aşınıma duyarlılık, kum, kil, çok ince kum, agregat stabilitesi ve dispersiyon oranı orta değişkenlik ve silt, iskelet yüzdesi, hidrolik geçirgenlik EC ve organik madde değerleri yüksek değişkenlik göstermiştir. E konusunda aşınıma duyarlılık, kum, silt, kil, hacim ağırlığı, dispersiyon oranı ve $\mathrm{pH}$ değerleri düşük değişkenlik, çok ince kum ve EC orta değişkenlik ve iskelet yüzdesi, agregat stabilitesi, hidrolik geçirgenlik, kireç ve organik madde değerleri yüksek değişkenlik göstermiştir. F konusunda aşınıma duyarlılık, kil, hacim ağırlığ kum, silt, çok ince kum ve agregat stabilitesi orta değişken, iskelet yüzdesi, hidrolik geçirgenlik, kireç ve organik madde içerikleri yüksek değişkenlik göstermiştir.

Araştırma konuları arasındaki farklılığın istatistiksel karşılaştırılması normal dağılım gösteren toprak özellikleri için t istatistiği ve normal dağılım göstermeyen toprak özellikleri için nonparametrik Mann-Whitney $U$ test istatistiği ile gerçekleştirilmiştir (Çizelge 3). Ele alınan toprak özelliklerinden $\mathrm{pH}$ değeri tüm konularda aynı grupta yer alırken diğer toprak özellikleri arasında konular arasında önemli farklılıklar meydana gelmiştir.

$\mathrm{K}$ faktör değerleri konular arasında istatistiksel farklılıklar göstermekle birlikte A, B, C ve E konularında orta aşınabilir, D ve F konularında kuvvetli aşınabilir topraklar olarak değerlendirilmiştir. Yakın zamanlarda ormandan işlemeli tarıma dönüştürülen arazide ( $\mathrm{F}$ Konusu) aşınıma duyarlılık değerlerindeki değişkenlik ve yüksek duyarlılık, sürekli orman (E Konusu) arazi kullanımına göre artmıştır. Muhtemeldir ki ilerleyen y1llarda F konusu arazilerin K Faktör değerlerindeki değişkenlik insan müdahalelerine bağlı olarak daha da 
artacaktır. Sürekli mera arazi kullanımı (D Konusu), genetiksel olarak yüksek aşınıma duyarlılık göstermiştir.

Toprakların tekstürel fraksiyonları (kum, çok ince kum, silt, kil) araştırma konularına göre farklılıklar göstermiştir. Bununla birlikte tekstür üzerinde, arazi kullanım türünün etkisi kısa dönemde beklenen durum değildir. Toprak tekstürel karakteristiklerindeki farklılık daha ziyade toprak genesisi ile ilişkilidir. Toprak oluşum koşulları toprakların tekstürel fraksiyonlarını belirler ve toprak tekstürünün değişimi arazi kullanım türleriyle kısa sürede anlamlı değişiklikler göstermez.

Araştırma yeri topraklarının agregat stabiliteleri tüm konularda oldukça yetersiz olduğu belirlenmiştir (Çizelge 1). İstatistiksel olarak $\mathrm{B}$ ve $\mathrm{F}$ konularına ait agregat stabilite değerleri arasındaki fark önemlidir. B Konusu (Belpınar Köyü tarım arazi kullanım türünden orman arazi kullanım türüne çevrilmiş arazi) agregat stabilite değeri $\% 40.53$ ve F Konusu (Binbaşıŏlu Köyü orman arazi kullanım türünden tarım arazi kullanım türüne çevrilmiş arazi) agregat stabilite değeri ise \%65.67 olmuştur. Sürekli orman arazisinin mera arazisine göre daha fazla oranda stabil agregat oluşturması, sürekli orman arazisinin daha fazla organik madde içeriğine sahip oluşunun bir sonucu olduğu düşünülmektedir. Nitekim Göl (2009) tarafindan
Karadeniz Bölgesi Dağdami nehri havzasında yapmış olduğu çalışma bulgusuna göre, mera arazisi $\% 60.4$ ve orman arazisi toprakları \%79.4 olarak daha yüksek suya dayanıklı agregat oranları göstermiştir. Diğer araştırma konuları agregat stabiliteleri arasında önemli bir farklılık bulunmamaktadır.

Toprakların hacim ağırlıkları arasındaki istatistiksel karşılaştırma $A$ ve $F, C$ ve $E, D$ ve $E$ ile $E$ ve $F$ konuları arasındaki farklılığın önemli olduğunu göstermiştir. A, C, D, E ve $\mathrm{F}$ konuları ortalama hacim ağırlıkları sırasıyla $1.56,1.63$, $1.69,1.47$ ve $1.74 \mathrm{~g} \mathrm{~cm}^{-3}$ olmuştur. Orman arazisinden tarım arazisine çevrilen F konusu en yüksek hacim ağırlığı ortalama değeri göstermiştir. $\mathrm{Bu}$ durum geçmişinde orman örtüsü bulunan bu arazide işlemeli tarıma dönüşümün olumsuz bir etkisi olarak değerlendirilmiştir. En yüksek hacim ağırlığının belirlendiği $\mathrm{F}$ konusu aynı zamanda en yüksek aşınıma duyarlılık faktör değerine sahip olması söz konusu arazinin sürdürülebilirliği için önlemler alınması gerekliliğini göstermektedir. Toprakların erozyona duyarlılık değerlerinin düşürülmesi için tarımsal kullanımdaki bu gibi arazilerde organik maddenin geliştirilmesi için baklagillerin de içinde yer alabileceği uygun ekim nöbeti programlarının uygulanması, organik madde birikimi sağlayacak örtü bitkili tarımsal

Çizelge 1. Araştırma konularının toprak özelliklerine ait bazı tanımlayıcı istatistikler.

Table 1. Some descriptive statistics of soil properties of research topics.

\begin{tabular}{|c|c|c|c|c|c|c|c|c|c|c|c|c|}
\hline Konu & Özellik & Ort. & SS & DK & Konu & Ortalama & SS & DK & Konu & Ortalama & SS & DK \\
\hline \multirow{14}{*}{ A } & $\mathrm{K}$ & 0.91 & 0.913 & 0.91 & \multirow{14}{*}{$\mathrm{C}$} & 0.16 & 0.031 & 19.55 & \multirow{14}{*}{ E } & 0.1360 & 0.015 & 11.03 \\
\hline & Kum, \% & 40.72 & 4.564 & 11.21 & & 44.51 & 5.369 & 12.06 & & 59.984 & 8.417 & 14.03 \\
\hline & Silt, \% & 25.13 & 4.387 & 17.46 & & 21.05 & 3.649 & 17.33 & & 20.266 & 2.295 & 11.32 \\
\hline & Kil, \% & 32.75 & 1.761 & 5.38 & & 34.44 & 3.937 & 11.43 & & 21.750 & 2.979 & 13.70 \\
\hline & Ç.İ.K & 13.34 & 3.00 & 22.50 & & 8.12 & 2.758 & 33.96 & & 12.848 & 4.282 & 33.33 \\
\hline & İ.Y & 13.19 & 8.269 & 62.70 & & 6.11 & 3.126 & 51.18 & & 6.9880 & 2.553 & 36.53 \\
\hline & A.S. & 55.69 & 19.207 & 34.49 & & 42.70 & 17.475 & 40.90 & & 49.906 & 8.687 & 17.41 \\
\hline & H.A. & 1.56 & 0.112 & 7.19 & & 1.63 & 0.118 & 7.22 & & 1.4734 & 0.100 & 6.79 \\
\hline & D.O. & 4.86 & 0.382 & 7.85 & & 5.21 & 0.489 & 9.39 & & 6.4840 & 0.950 & 14.65 \\
\hline & H.G. & 2.87 & 0.005 & 0.19 & & 4.37 & 1.791 & 40.97 & & 16.620 & 5.999 & 36.10 \\
\hline & Kireç, \% & 18.79 & 3.767 & 20.05 & & 31.55 & 1.071 & 3.39 & & 15.776 & 5.864 & 37.17 \\
\hline & $\mathrm{pH}$ & 7.72 & 0.084 & 1.08 & & 7.76 & 0.055 & 0.71 & & 7.6600 & 0.167 & 2.18 \\
\hline & EC & 364.00 & 83.247 & 22.87 & & 510.00 & 126.293 & 24.76 & & 278.00 & 69.42 & 24.97 \\
\hline & O.M. & 1.162 & 0.587 & 50.55 & & 1.45 & 0.258 & 17.83 & & 2.9080 & 1.388 & 47.73 \\
\hline \multirow{14}{*}{ B } & $\mathrm{K}$ & 0.160 & 0.048 & 30.30 & \multirow{14}{*}{ D } & 0.21 & 0.056 & 27.18 & \multirow{14}{*}{ F } & 0.2680 & 0.040 & 14.93 \\
\hline & Kum, $\%$ & 49.56 & 7.077 & 14.28 & & 39.04 & 12.850 & 32.92 & & 41.974 & 8.624 & 20.55 \\
\hline & Silt, $\%$ & 23.90 & 4.362 & 19.93 & & 26.53 & 12.770 & 48.14 & & 30.358 & 7.083 & 23.33 \\
\hline & Kil, \% & 28.54 & 6.723 & 23.56 & & 34.44 & 8.406 & 24.41 & & 27.00 & 3.82 & 14.15 \\
\hline & Ç.İ.K, \% & 7.79 & 3.701 & 47.54 & & 11.69 & 3.465 & 29.64 & & 15.838 & 3.851 & 24.31 \\
\hline & İ.Y & 0.16 & 0.048 & 30.30 & & 4.26 & 2.598 & 60.93 & & 11.214 & 5.383 & 48.00 \\
\hline & A.S. & 40.53 & 19.480 & 48.06 & & 47.54 & 15.010 & 31.57 & & 65.672 & 13.28 & 20.22 \\
\hline & H.A. & 1.61 & 0.246 & 15.34 & & 1.69 & 0.138 & 8.16 & & 1.735 & 0.119 & 6.86 \\
\hline & D.O. & 5.79 & 0.943 & 16.29 & & 4.90 & 1.158 & 23.65 & & 5.024 & 0.671 & 13.36 \\
\hline & H.G. & 8.98 & 6.647 & 74.04 & & 5.67 & 5.666 & 99.89 & & 6.644 & 5.080 & 76.46 \\
\hline & Kireç, \% & 21.56 & 2.871 & 13.32 & & 20.12 & 2.553 & 12.69 & & 29.88 & 5.336 & 17.86 \\
\hline & $\mathrm{pH}$ & 7.70 & 0.141 & 1.84 & & 7.70 & 0.324 & 4.21 & & 7.760 & 0.114 & 1.47 \\
\hline & $\mathrm{EC}$ & 256.00 & 49.799 & 19.45 & & 338.00 & 190.100 & 56.24 & & 280.00 & 21.21 & 7.58 \\
\hline & O.M. & 1.42 & 0.856 & 60.02 & & 1.01 & 0.462 & 45.74 & & 1.154 & 0.633 & 54.85 \\
\hline
\end{tabular}

Kısaltmalar: Ort.: Ortalama, SS: Standart sapma, DK, Değişim katsayısı; K (t h MJ ${ }^{-1} \mathrm{~mm}^{-1}$ ): Toprak aşınıma duyarlılığı; Ç.İ.K (\%): Çok ince kum; İ.Y. (\%): İskelet yüzdesi; A.S. (\%): Agregat stabilitesi; H.A. $\left(\mathrm{g} \mathrm{cm}^{-3}\right)$ : Hacim ağırlı̆̆ı; D.O. (\%): Dispersiyon oranı; H.G. $\left(\mathrm{mm} \mathrm{h}^{-1}\right)$ : Hidrolik geçirgenlik; EC $\left(\mu \mathrm{S} \mathrm{cm}^{-1}\right)$ : Elektriksel iletkenlik; O.M. (\%): Organik madde. 
Çizelge 2. Araştırma konularına ait toprak özellikleri.

Table 2. Soil properties of research topics.

\begin{tabular}{|c|c|c|c|c|c|c|c|c|c|c|c|c|c|c|}
\hline \multirow{2}{*}{ Tek } & \multicolumn{14}{|c|}{ Toprak Özelliği } \\
\hline & $\mathrm{K}$ & Kum, \% & Silt, $\%$ & Kil, \% & Ç.İ.K & İ.Y. & A.S. & H.A. & D.O. & H.G. & Kireç, \% & $\mathrm{pH}$ & $\mathrm{EC}$ & O.M. \\
\hline A1 & 0.18 & 46.62 & 21.05 & 32.33 & 11.21 & 24.12 & 62.29 & 1.69 & 5.37 & 4.95 & 18.16 & 7.8 & 280 & 0.82 \\
\hline $\mathrm{A} 2$ & 0.07 & 36.09 & 29.47 & 34.44 & 13.16 & 19.55 & 53.33 & 1.41 & 4.48 & 4.40 & 20.70 & 7.7 & 400 & 0.72 \\
\hline A3 & 0.09 & 36.09 & 29.47 & 34.44 & 18.45 & 10.16 & 83.80 & 1.59 & 4.48 & 4.40 & 21.87 & 7.8 & 340 & 1.00 \\
\hline A4 & 0.20 & 42.40 & 25.27 & 32.33 & 11.08 & 4.88 & 47.02 & 1.62 & 5.00 & 5.14 & 20.70 & 7.7 & 310 & 1.09 \\
\hline A5 & 0.15 & 42.40 & 20.37 & 30.23 & 12.82 & 7.24 & 32.00 & 1.48 & 4.98 & 6.36 & 12.50 & 7.6 & 490 & 2.18 \\
\hline B1 & 0.13 & 42.40 & 21.06 & 36.54 & 2.32 & 3.50 & 21.95 & 1.47 & 4.99 & 2.81 & 20.31 & 7.7 & 240 & 0.52 \\
\hline B2 & 0.14 & 48.72 & 18.95 & 32.33 & 6.30 & 5.00 & 41.59 & 1.38 & 5.58 & 4.88 & 19.92 & 7.5 & 300 & 1.51 \\
\hline B3 & 0.24 & 46.62 & 29.47 & 23.91 & 11.47 & 5.10 & 60.57 & 1.49 & 5.37 & 11.65 & 23.43 & 7.7 & 300 & 0.65 \\
\hline B4 & 0.12 & 61.35 & 18.95 & 19.70 & 10.8 & 35.83 & 58.85 & 2.00 & 7.42 & 19.33 & 18.55 & 7.9 & 180 & 2.56 \\
\hline B5 & 0.17 & 48.72 & 21.05 & 30.23 & 8.04 & 7.48 & 19.69 & 1.67 & 5.59 & 6.22 & 25.58 & 7.7 & 260 & 1.88 \\
\hline $\mathrm{C} 1$ & 0.18 & 36.09 & 23.16 & 40.75 & 7.93 & 11.68 & 52.20 & 1.46 & 4.49 & 1.96 & 30.20 & 7.7 & 570 & 1.12 \\
\hline $\mathrm{C} 2$ & 0.14 & 44.51 & 21.05 & 34.44 & 6.68 & 4.96 & 66.23 & 1.76 & 5.17 & 3.94 & 31.83 & 7.8 & 340 & 1.79 \\
\hline C3 & 0.11 & 50.83 & 14.73 & 34.44 & 4.42 & 4.84 & 36.75 & 1.71 & 5.85 & 3.66 & 33.01 & 7.8 & 420 & 1.35 \\
\hline $\mathrm{C} 4$ & 0.18 & 44.51 & 23.16 & 32.33 & 10.36 & 4.79 & 19.83 & 1.62 & 5.17 & 6.03 & 31.83 & 7.8 & 650 & 1.61 \\
\hline C5 & 0.17 & 46.62 & 23.15 & 30.23 & 11.22 & 4.27 & 38.48 & 1.58 & 5.37 & 6.26 & 30.86 & 7.7 & 570 & 1.37 \\
\hline D1 & 0.12 & 46.62 & 8.42 & 44.96 & 9.30 & 3.25 & 66.15 & 1.86 & 5.37 & 0.55 & 20.89 & 8.1 & 140 & 0.61 \\
\hline D2 & 0.27 & 25.56 & 42.11 & 32.33 & 8.49 & 2.85 & 38.95 & 1.50 & 3.85 & 5.77 & 17.97 & 7.8 & 270 & 1.34 \\
\hline D3 & 0.24 & 29.77 & 33.69 & 36.54 & 13.12 & 7.94 & 53.33 & 1.74 & 4.08 & 3.60 & 24.22 & 7.7 & 350 & 1.39 \\
\hline D4 & 0.21 & 36.09 & 27.37 & 36.54 & 10.50 & 5.84 & 26.92 & 1.73 & 4.49 & 3.19 & 19.14 & 7.2 & 650 & 0.41 \\
\hline D5 & 0.19 & 57.14 & 21.05 & 21.84 & 17.04 & 1.44 & 52.35 & 1.60 & 6.69 & 15.25 & 18.36 & 7.7 & 280 & 1.30 \\
\hline E1 & 0.16 & 73.46 & 18.94 & 17.60 & 16.39 & 8.20 & 51.36 & 1.59 & 7.85 & 26.75 & 16.79 & 7.7 & 310 & 2.51 \\
\hline E2 & 0.14 & 50.83 & 23.15 & 26.02 & 12.35 & 8.47 & 57.89 & 1.47 & 5.83 & 10.73 & 14.84 & 7.5 & 280 & 4.18 \\
\hline E3 & 0.13 & 57.14 & 21.05 & 21.81 & 16.98 & 4.20 & 49.38 & 1.41 & 6.68 & 14.61 & 6.25 & 7.7 & 340 & 4.43 \\
\hline E4 & 0.12 & 61.35 & 17.14 & 21.51 & 12.24 & 9.74 & 35.55 & 1.34 & 5.37 & 15.76 & 20.11 & 7.5 & 300 & 2.32 \\
\hline E5 & 0.13 & 57.14 & 21.05 & 21.81 & 6.28 & 4.33 & 55.35 & 1.54 & 6.69 & 15.25 & 20.89 & 7.9 & 160 & 1.10 \\
\hline $\mathrm{F} 1$ & 0.32 & 27.62 & 42.10 & 30.23 & 15.35 & 2.44 & 61.59 & 1.64 & 3.97 & 6.65 & 26.36 & 7.7 & 280 & 0.44 \\
\hline $\mathrm{F} 2$ & 0.29 & 44.51 & 27.37 & 28.12 & 17.12 & 15.3 & 63.79 & 1.67 & 5.17 & 1.69 & 25.00 & 7.8 & 300 & 0.94 \\
\hline F3 & 0.26 & 50.83 & 25.26 & 23.91 & 21.55 & 13.2 & 78.26 & 1.88 & 5.83 & 11.94 & 36.52 & 7.8 & 250 & 1.40 \\
\hline F4 & 0.21 & 42.4 & 25.27 & 32.33 & 11.23 & 9.93 & 46.46 & 1.84 & 4.98 & 1.44 & 26.75 & 7.9 & 300 & 2.11 \\
\hline F5 & 0.26 & 44.51 & 31.79 & 23.70 & 13.94 & 15.38 & 78.26 & 1.62 & 5.17 & 11.5 & 34.76 & 7.6 & 270 & 0.88 \\
\hline
\end{tabular}

Kısaltmalar: Tek: Tekerrür; $\mathrm{K}\left(\mathrm{t} \mathrm{h} \mathrm{MJ} \mathrm{mm}^{-1}\right.$ ): Toprak aşınıma duyarlılı̆̆; C.İ.K (\%): Çok ince kum; İ.Y. (\%): İskelet yüzdesi; A.S. (\%): Agregat stabilitesi, H.A. $\left(\mathrm{g} \mathrm{cm}^{-3}\right)$ : Hacim ağırlığı; D.O. (\%): Dispersiyon oranı; H.G. $\left(\mathrm{mm} \mathrm{h}^{-1}\right)$ : Hidrolik geçirgenlik; EC $\left(\mu \mathrm{S} \mathrm{cm}{ }^{-1}\right)$ : Elektriksel iletkenlik; O.M. (\%): Organik madde.

Çizelge 3. Araştırma konularına ait toprak özelliklerinin istatistiksel analizi.

Table 3. Statistical analysis of soil properties belonging to research topics.

\begin{tabular}{|c|c|c|c|c|c|c|c|c|c|c|c|c|c|c|}
\hline \multirow[t]{2}{*}{ Konu } & \multicolumn{14}{|c|}{ Toprak Özelliği } \\
\hline & $\mathrm{K}$ & Kum, \% & Silt, \% & Kil, \% & Ç.İ.K & İ.Y. & A.S. & H.A. & D.O. & H.G. & Kireç & $\mathrm{pH}$ & $\mathrm{EC}$ & O.M. \\
\hline A & $0.14^{\mathrm{ae}}$ & $40.72^{\mathrm{a}}$ & $25.13^{\text {ba }}$ & $32.75^{\mathrm{a}}$ & $13.3^{\mathrm{a}}$ & $13.2^{\mathrm{a}}$ & $55.7^{\mathrm{ab}}$ & $1.6^{\mathrm{a}}$ & $4.9^{\mathrm{a}}$ & $5.1^{\mathrm{a}}$ & $18.8^{\mathrm{a}}$ & $7.7^{\mathrm{a}}$ & $364^{\mathrm{ac}}$ & $1.16^{\mathrm{ad}}$ \\
\hline B & $0.16^{\mathrm{cad}}$ & $49.56^{\mathrm{bc}}$ & $21.90^{\text {ba }}$ & $28.54^{\mathrm{ab}}$ & $7.8^{\mathrm{bc}}$ & $11.4^{\mathrm{ac}}$ & $40.5^{\mathrm{a}}$ & $1.6^{\mathrm{ba}}$ & $5.8^{\mathrm{ab}}$ & $9.0^{\mathrm{ab}}$ & $21.6^{\mathrm{a}}$ & $7.7^{\mathrm{a}}$ & $256^{\mathrm{b}}$ & $1.42^{\mathrm{acd}}$ \\
\hline $\mathrm{C}$ & $0.16^{\mathrm{cad}}$ & $44.51^{\mathrm{ac}}$ & $21.05^{\mathrm{a}}$ & $34.44^{\mathrm{a}}$ & $8.1^{\mathrm{bc}}$ & $6.1 \mathrm{a}^{\mathrm{e}}$ & $42.7^{\mathrm{a}}$ & $1.6^{\mathrm{ba}}$ & $5.2^{\mathrm{a}}$ & $4.4^{\mathrm{ca}}$ & $31.6^{\mathrm{b}}$ & $7.8^{\mathrm{a}}$ & $510^{\mathrm{c}}$ & $1.45^{\mathrm{ad}}$ \\
\hline D & $0.21^{\mathrm{cab}}$ & $39.04^{\mathrm{ac}}$ & $26.53^{\mathrm{ba}}$ & $34.44^{\text {ad }}$ & $11.7^{\mathrm{ac}}$ & $4.3 b^{\text {ce }}$ & $47.5^{\mathrm{ab}}$ & $1.7^{\mathrm{ba}}$ & $4.9^{\mathrm{a}}$ & $5.7^{\mathrm{da}}$ & $20.1^{\mathrm{ac}}$ & $7.7^{\mathrm{a}}$ & $338^{\mathrm{abc}}$ & $1.01^{\mathrm{ae}}$ \\
\hline $\mathrm{E}$ & $0.14^{\mathrm{ed}}$ & $59.98^{\mathrm{b}}$ & $20.27^{\mathrm{a}}$ & $21.75^{\mathrm{ce}}$ & $12.8^{\mathrm{ac}}$ & $7.00^{\mathrm{ae}}$ & $49.9^{\mathrm{ab}}$ & $1.5^{\mathrm{a}}$ & $6.5^{\mathrm{b}}$ & $16.6^{\mathrm{b}}$ & $15.8^{\mathrm{a}}$ & $7.7^{\mathrm{a}}$ & $278^{\text {ba }}$ & $2.91^{\mathrm{bc}}$ \\
\hline $\mathrm{F}$ & $0.27^{\mathrm{b}}$ & $41.97^{\mathrm{ac}}$ & $30.36^{\mathrm{b}}$ & $27.66^{\mathrm{db}}$ & $15.8^{\mathrm{a}}$ & $11.2^{\mathrm{a}}$ & $65.7^{\mathrm{bc}}$ & $1.7^{\mathrm{b}}$ & $5.0^{\mathrm{a}}$ & $6.6^{\mathrm{ca}}$ & $29.9^{b c}$ & $7.8^{\mathrm{a}}$ & $280^{\mathrm{ba}}$ & $1.15^{\mathrm{d}}$ \\
\hline
\end{tabular}

Kısaltmalar: K (t h MJ${ }^{-1} \mathrm{~mm}^{-1}$ ):Toprak aşınıma duyarlılı̆̆ 1 C C.I.K (\%): Çok ince kum; İ.Y. (\%): İskelet yüzdesi; A.S. (\%): Agregat stabilitesi, H.A. (g cm ${ }^{-3}$ ): Hacim ağırlığı; D.O. (\%): Dispersiyon oranı; H.G. $\left(\mathrm{mm} \mathrm{h}^{-1}\right)$ : Hidrolik kondaktivite; EC $\left(\mu \mathrm{S} \mathrm{cm}{ }^{-1}\right)$ : Elektriksel iletkenlik; O.M. (\%): Organik madde.

faaliyetler, minimum toprak işleme, toprakların devirerek işlenmesi yerine yırtarak işlenmesi ve bu sayede uzun süreli toprak neminin ve organik madde oluşumuna katkıda bulunulması, malç örtülü tarım, tesviye eğrilerine paralel şeritvari tarım gibi tarımsal uygulamalar fayda sağlayacaktır. A ve $\mathrm{F}$ konuları güncel olarak işlemeli tarım kullanımında olmakla beraber ormandan tarımsal kullanıma çevrilmiş $F$ Konusu toprakların hacim ağırlıkları daha yüksek olmuştur. Binbaşığlu Köyünde yer alan sürekli orman arazisi topraklarının ortalama hacim ağırlıkları (C Konusu), sürekli tarım arazisi olan E konusuna göre daha düşük olmuştur. Etiyopya'nın Kuyu ilçesinde yürütülen bir çalışmada ağır otlatılmış mera ve işlemeli tarım arazileri hacim ağırlıkları yakın değerler göstermiş $\left(1.38 \mathrm{~g} \mathrm{~cm}^{-3}\right)$, en düşük hacim ağırlığı değerleri ise mera $\left(1.09 \mathrm{~g} \mathrm{~cm}^{-3}\right)$ ve orman $\left(1.15 \mathrm{~g} \mathrm{~cm}^{-3}\right)$ topraklarında belirlendiği rapor edilmiştir (Tufa ve ark. 2019). Ormandan işlemeli tarım arazisine çevrilmiş (F Konusu) arazinin sürekli orman arazi kullanımında olan E Konusuna göre daha yüksek hacim ağırlığı göstermiştir. 
Araştırma konuları toprakların dispersiyon oranları belirlenmiştir. Dispersiyon oranı değeri $\% 15^{\prime}$ ten büyük toprakların erozyona dayanıksız, küçük olanların dayanıklı olduğu birçok araştırmacı tarafından rapor edilmiştir (Sönmez 1994). Tüm konular için olmak üzere dispersiyon oran değerleri \%15'in altında olmuştur. $\mathrm{Bu}$ erozyon eğilim indeksine göre, araştırma konularının tamamının su erozyonuna dirençli olduğu sonucu bulunmuştur. Dispersiyon oranı değerleri toprak aşınıma duyarlılık (K Faktör) değerleriyle karşılaştırıldığında bu durum kısmen teyit edilmektedir.

Dispersiyon oranları dikkate alındığında A (sürekli tarım arazisi) ve $\mathrm{E}$ konusu (sürekli orman arazisi), C (sürekli tarım) ve E Konusu, D (sürekli mera) ve E Konusu ile E ve F (ormandan işlemeli tarıma dönüştürülmüş arazi) konuları anlamlı farklılıklar göstermiştir. Sürekli tarım arazisi (A Konusu), sürekli orman arazisine göre daha yüksek bir dispersiyon oranı göstermiştir. Yine işlemeli tarım arazisi (C Konusu), $\mathrm{E}$ konusuna göre aynı yönde önemli farklılık göstermiştir. Sürekli orman arazisinin (E Konusu) dispersiyon oranı sürekli mera arazisine (F konusu) göre daha yüksek olmuştur.

Araştırma konuları doygun hidrolik geçirgenlikleri orta, orta hızlı ve hızlı olmuştur. Yapılan istatistiksel karşılaştırmaya göre $A$ ve $E, C$ ve $E, D$ ve $E$ ile $E$ ve $F$ arasındaki su geçirgenliği farkı önemli bulunmuştur. Sürekli tarım yapılan A konusu toprakların geçirgenlik değerleri sürekli orman örtüsü altında bulunan $\mathrm{E}$ konusu topraklara göre daha düşük olmuştur. İşlemeli tarım, toprakların makropor içeriğini mesopor içeriği lehine azaltır. $\mathrm{Bu}$ durum toprakların su geçirgenliğinde azalmaya yol açar ve eğimli arazilerde yüzey akış oluşturma potansiyelinde artışa neden olur. İşlenmeyen orman arazileri makroporlarını geliştirerek daha fazla geçirgenlik ve düşük yüzey akış potansiyeli taşırlar. Benzer durum Binbaşığlu köyü tarım arazisi (C Konusu) için de geçerlidir. Sürekli mera arazisi sürekli orman arazisine göre daha düşük su geçirgenliği değeri göstermiştir. Göl (2009) Dağdami havzasındaki çalışma bulgusuna göre, hidrolik geçirgenlik değerleri mera arazisinde ortalama $8.4 \mathrm{~cm}^{3} \mathrm{~s}^{-1}$ olmuş, orman arazisinde ise $82.4 \mathrm{~cm}^{3} \mathrm{~s}^{-1}$ olarak daha düşük değere sahip olduğunu rapor edilmiştir. Ormandan tarıma dönüştürülmüş arazinin su geçirgenliği sürekli orman arazi kullanım türüne göre daha az olmuştur.

Araştırma kapsamında toprakların kireç içerikleri farklı arazi kullanım türleri dikkate alınarak karşılaştırılmıştır. A ve $C$, $A$ ve $F, B$ ve $C, B$ ve $F, C$ ve $D, C$ ve $E$ ile $E$ ve $F$ konuları toprak kireç içerikleri ortalamalar arası farklılık önemli bulunmuştur. Belpınar Köyü ve Binbaşığlu Köyünde yer alan ve aynı arazi kullanımında (tarım arazisi) olmalarına rağmen kireç içeriklerindeki anlamlı farklılık yerel ana materyal ve topografik özellikler ile ilişkili olduğu düşünülmektedir. Sürekli tarım (A Konusu) ile ormandan tarımsal kullanıma dönüștürülen (F Konusu) arazinin kireç içerikleri karşıllaştırıldığında arazi kullanım değişikliği gerçekleştirilen F Konusunda daha fazla kireç içeriği belirlenmiştir. Birbirlerine yakın konumda yer alan Binbaşıŏlu mera ve tarım arazisi karşılaştırıldığında tarım arazisinin kireç içeriği daha fazla olmuştur. Toprakların kireç içeriği kuşkusuz arazi kullanım türleriyle ilişkili değişiklikler göstermektedir. Ancak çalışma bulgularına göre, toprak kireç içeriklerine ana materyale ait kireç kapsamı, iklim ve topografya gibi diğer toprak oluşturan faktörler daha fazla etkili olmuştur.

Toprakların elektriksel iletkenlikleri ile arazi kullanım türleri arasındaki ilişkiler araştııılmıştır. A ve $\mathrm{E}, \mathrm{C}$ ve $\mathrm{E}$ ile $\mathrm{E}$ ve $\mathrm{F}$ arasındaki farklılık önemli olmuştur. Genel olarak işlemeli tarımsal kullanımdaki arazilere uygulanan gübrelerin tuz etkisi sebebiyle daha yüksek EC değerlerine sahip olması beklenir. İran'ın batısında yer alan Zagros ormanlarında yapılmış bir çalışma sonucuna göre, geçmiş dönemde tahrip edilerek tarım, meyve bahçesi ve tarımsal ormancılık arazi kullanım türlerine dönüşmüş toprakların elektriksel iletkenlik değerlerinde artış meydana geldiği bildirilmiştir (Samani ve ark. 2020).

Çalışmada incelenen arazi kullanımları organik madde kapsamları bakımından önemli farklılıklar göstermiştir. Organik madde içerikleri dikkate alındığında A (sürekli tarım arazisi) ve E konusu (sürekli orman arazisi), C (sürekli tarım) ve E konuları, D (sürekli mera) ve E konuları, D ve F (ormandan işlemeli tarıma dönüştürülmüş arazi) konuları ile $E$ ve $F$ konuları anlamlı farklılıklar göstermiştir. Ürdün'de yürütülen bir araştırma sonucuna göre Ajloun yöresinde sürekli orman örtüsü altında yer alan topraklar dışında işlemeli tarım arazilerinin organik madde kapsamı "az" olduğu bildirilmiştir. Çalışmada ayrıca orman ve ekili alanlar arasındaki organik madde içeriğindeki farklılık istatistiksel olarak önemli bulunmuştur (Khresat ve ark. 2008). Çalışmamızda sürekli mera arazisi ve geçmişinde işlemeli tarım arazi kullanım türünde iken ormana dönüştürülen arazi de dahil olmak üzere toprakların organik madde kapsamı yetersiz bulunmuştur.

\section{Sonuç}

Tokat-Zile ilçesine bağlı Binbaşığlu ve Belpınar köylerinde yürütülen bu çalışmada, arazi kullanım türü değişiklilerinin bazı toprak fiziksel ve kimyasal özelliklerine etkisinin araştırılması amaçlanmıştır.

Yapılan çalışmalar sonucunda $F$ konusu (Binbaşığlu ormandan tarıma dönüştürülen alan) ile B konusuna (Belpınarı tarımdan ormana çevrilen alan) ait ele alınan toprak özellikleri arasında bariz bir farklılığın henüz oluşmamasının, her iki konuda da meydana gelen arazi kullanım değişikliklerinin 10 yıldan az bir sürede gerçekleşmesinden kaynaklandığ 1 düşünülmektedir.

E konusunda (sürekli orman arazisi), diğer araştırma konularına göre toprak özelliklerinde çok fazla farkın oluşmaması, sürekli orman örtüsü altında bulunmasına rağmen, mevcut orman örtüsünün yeterince yoğun olmaması nedeniyle yüzey akışa ve toprak kayıplarına açık konumundan kaynaklanmaktadır. Sonuçta tarım arazisi kadar olmasa da aktif erozyonla ince materyalini kaybetmekte olduğu ve yeterince organik madde birikimini sağlayabilecek bir örtü yoğunluğuna sahip olmadığı değerlendirilmektedir. E konusunda bariz olmamakla beraber oluşan bazı farklılıkların sürekli mera arazisi hariç diğer konulara göre tarımsal işleme ve insan elinin yeterince değmemiş olması ve bir miktar bitkisel artığın kısmen toprakta birikiminden kaynaklandığı düşünülmektedir.

Tüm araştırma konularında belirlenen dispersiyon oran değerlerinin tamamının eşik değer olan \%15'in altında oluşu, toprakların su erozyonuna karşı dirençli olduğunu ortaya koymuştur.

Binbaşığlu köyü ve Belpınar köyü topraklarının pH değerleri arasında önemli bir fark görülmemiştir. Binbaşığlu köyü ve Belpınar köyü topraklarının Belpınar sürekli tarım arazisi ile Binbaşığlu sürekli orman ve Binbaşığlu ormandan tarıma dönüşmüş arazi topraklarının kil içerikleri arasındaki farklılık istatistiksel olarak önemli değişiklik göstermiştir ve diğer konularla ilgili herhangi bir kayda değer farklılık bulunmamaktadır. 
Yapılan araştırmalar sonucunda mera arazisi çıplak ve kayalıklara sahip bir alan olarak göze çarpmaktadır. Araştırma yeri tarım, mera ve orman alanlarında ciddi sorunlar bulunmaktadır. Bu sorunlar dikkate alınarak gerekli çözümler kapsamlı bir şekilde ele alınmalıdır. Orman arazilerinde ve ormana dönüştürülen arazide fazla kırımın yapılmaması ve bitki sıklığının artırılması gerekmektedir. Mera bölgesinde aşırı otlatma yapılmamalı, yem bitkileri çeşitliliği sağlanmalı ve düzenli gübreleme işlemleri yapılmalıdır. Tarımsal faaliyetlerin yapıldığı alanlarda ise toprak analiz sonuçlarına göre gübreleme, ekim nöbeti uygulamaları ve korumalı toprak işleme yöntemleri uygulanarak topraktaki organik madde miktarı artırılabilir. Yapılan bu işlemler sonucunda toprağın su erozyonuna dayanıklılığının da artması gerçekleştirilecektir.

$\mathrm{Bu}$ çalışma ile ele alınan toprak özelliklerinin, arazi kullanımı ile fazla değişim göstermediği görülmüştür. Belirlenen farklılıkların bir kısmının toprak genesisinden kaynaklandığı düşünülmektedir. Buna karşı tarımsal uygulamalarla değişim gösterebilen toprak özelliklerinde anlamlı farklılıklar oluşmuştur. Bu nedenle tarımsal kullanım konusunda gerekli önlemler alınmalı ve toprak özelliklerini güçl0endirici girdiler uygulanmalıdır.

Yapılacak benzer çalışmalarda, arazi kullanım değissikliklerin toprak özelliklerine olan etkisinin daha bariz olarak ortaya çıkabilmesi için, bu değişikliklerin daha uzun zaman önce gerçekleşmiş olduğu lokasyonların çalışma alanı olarak seçilmesi önerilmektedir.

\section{Kaynaklar}

Baker CJ, Saxton KE, Ritchie WR, Chamen WCT, Reicosky DC, Ribeiro F, Justice SE, Hobbs PR (2007) No-tillage Seeding in Conservation Agriculture. Food and Agriculture Organization of the United Nations, pp. 341.

Banger K, Kukal SS, Toor G, Sudhir K, Hanumanthraju TH (2009) Impact of long term addition of chemical fertilizer and farm yard manure on carbon and nitrogen sequestration under rice-cowpea cropping system in semi-arid tropics. Plant and Soil 318: 27-35.

Bryan RB (1968) The devolopment use and efficiency of indices of soil erodibility. Geoderma 2(1): 5-26.

Dias FPM, Hubner R, Nunes FD, Leandro WM, Xavier FAD (2019) Effects of land-use change on chemical attributes of a Ferralsol in Brazilian Cerrado. Catena 177: 180-188.

Duguma LA, Hager H, Sieghardt M (2010) Effects of land use types on soil chemical properties in small holder farmers of Central Highland Ethiopia. Ekológia (Bratislava) 29(1): 1-14.

Eynard A, Shumacher TE, Lindstrom MJ, Malo DD (2004) Aggregate sizes and stability in cultivated South Dakota prairie ustolls and usterts. Soil Science Society of America Journal 68: 1360-1365.

Göl C (2009) The effects of land use change on soil properties and organic carbon at Dagdami river catchment in Turkey. Journal of Environmental Biology 30(5): 825-830.

Hartemink AE, Veldkamp T, Bai Z (2008) Land cover change and soil fertility decline intropical regions. Turkish Journal of Agriculture and Forestry 32: 195-213.

Holeplass H, Singh BR, Lal R (2004) Carbon sequestration in soil aggregates under different crop rotation and nitrogen fertilization in an Inceptisol in southeastern Norway Nutrient Cycling in Agroecosystems 70: 167-177.

Khresat S, Al-Bakri J, Al-Tahhan R (2008) Impacts of land use/cover change on soil properties in the Mediterranean Region of Northwestern Jordan. Land Degradation Development 19: 397-407.
Kiflu A, Beyene S (2013) Effects of different land use systems on selected soil properties in South Ethiopia. Journal of Soil Science and Environment Management 4(5): 100-107.

Lal R (2002) Soil carbon dynamics in cropland and rangeland. Environmental Pollution 116: 353-362.

Lemenih M, Karltun E, Olsson M (2005) Soil organic matter dynamics after deforestation along a farmfield chronosequence in southern highlands of Ethiopia. Agriculture, Ecosystems and Environment 109: 9-19.

Maral Z (2016) Kastamonu yöresinde arazi kullanım farklılığın karbon ve azot tutumuna olan etkisi. Yüksek Lisans Tezi, Kastamonu Üniversitesi, Fen Bilimleri Enstitüsü, Kastamonu.

MGM (2019) Tarım Orman Bakanlığı, Meteoroloji İşleri Genel Müdürlüğü Zile İlçesi uzun yıllık meteorolojik verileri (Yazılı Görüş̧e).

Oral HV (2010) Impacts of land use change on soil respiration and elemental carbon in the forests of Karasu District. Doktora Tezi, Boğaziçi Üniversitesi Çevre Bilimi Enstitüsü, İstanbul.

Özdemir R (2019) Manisa Demirci yöresinde farklı arazi kullanım şekilleri altındaki toprakların bazı fiziksel ve kimyasal özelliklerinin araştırılması. Yüksek Lisans Tezi, Isparta Uygulamalı Bilimler Üniversitesi, Lisansüstü Eğitim Enstitüsü, Isparta.

Powers JS (2004) Changes in soil carbon and nitrogen after contrasting land-use transitions in northeastern Costa Rica. Ecosystems 7: 134146.

Samani KM, Pordel N, Hosseini V, Shakeri Z (2020) Effect of land-use changes on chemical and physical properties of soil in western Iran (Zagros oak forests). Journal of Forestry Research 31(2): 637-647.

Saxton KE, Rawls WJ (2006) Soil water characteristic estimates by texture and organic matter for hydrologic solutions. Soil Science Society of America Journal 70: 1569-1578.

Scheffler R, Neill C, Krusche AV, Elsenbeer H (2011) Soil hydraulic response to land-use change associated with the recent soybean expansion at the Amazon agricultural frontier. Agricultural Ecosystem Environment 144: 281-289.

Shepherd TG, Saggar S, Newman RH, Ross CW, Dando JL (2001) Tillage-induced change to soil structure and organic carbon fraction in New Zealand soils. Australian Jounal of Soil Research 39: 465489.

Sönmez K (1994) Toprak Koruma. Atatürk Üniversitesi Ziraat Fakültesi Yayınları, No: 169, Erzurum.

SPSS (2011) IBM Statistical Package for the Social Sciences (SPSS) Statistics 21.0 for Windows. Armonk, NY.

Tufa M, Melese A, Tena W (2019) Effects of land use types on selected soil physical and chemical properties: The case of Kuyu District, Ethiopia. Eurasian Journal of Soil Science 8(2): 94-109.

Tüzüner A (1990) Toprak ve Su Analiz El Kitabı. Köy Hizmetleri Genel Müdürlüğü, Ankara.

Ufot UO, Iren OB, Njoku CU (2016) Effects of land use on soil physical and chemical properties in Akokwa area of Imo State, Nigeria. International Journal of Life Sciences Scientific Research 2(3): 273-278.

Upchurch DR, Wilding LP, Hatfield JL (1988) Methods to evaluate spatial variability. In: Hossner LR (Ed) Reclamation of SurfaceMinedlands. CRC Press, Inc., Florida.

Wischmeier WH, Smith DD (1978) Predicting rainfall erosion losses. Agriculture Handbook 537, USDA, Washington, D.C., USA. 